ARCHIVO ESPAÑOL DE ARTE, LXXX, 319

JULIO-SEPTIEMBRE 2007, pp. 275-288

ISSN: 0004-0428

\title{
LA CASA PROFESA DE LOS JESUITAS EN MADRID Y UNA SERIE DE PINTURAS ADQUIRIDAS POR CARLOS III
}

\author{
POR \\ ANDRÉS SÁNCHEZ LÓPEZ \\ Doctor en Historia del Arte
}

\begin{abstract}
La Casa Profesa de los Jesuitas en Madrid y una serie de pinturas adquiridas por Carlos III. El estudio supone una reconstrucción de la fundación de la Casa Profesa de los Jesuitas de Madrid así de cómo debía ser el templo. Este edificio, uno de los más importantes de la Capital en el siglo XVII, desapareció desafortunadamente en el s. XIX con el cambio urbanístico que sufrió la calle Mayor. Gracias a una serie de pinturas que Carlos III adquirió tras la expulsión de los Jesuitas podemos hacernos una idea de las importantes obras de arte que ornaban este templo. El estudio sirve también para la localización y estudio de estas obras todas ellas de gran interés artístico pues fueron realizadas por algunos de los más importantes pintores del s. XVII como Luca Giordano, Murillo o Pedro Orrente, así como maestros del siglo XVI italiano tales como Andrea del Sarto o Gerolamo Muziano.
\end{abstract}

Palabras clave: Jesuitas; Casa Profesa; Madrid; Pintura; Arquitectura; Siglos XVII-XVIII.

This study deals with the reconstruction -both architectonic and pictorial- of the $17^{\text {th }}$-century Main House (Casa Profesa) and church of the Jesuits in Madrid, unfortunately destroyed during the $19^{\text {th }}$ century due to the urban reforms carried out on the calle Mayor. Thanks to a series of paintings acquired by Carlos III following the expulsion of the Jesuits from Spain (1767), it is possible to have an idea of the important works that once adorned this temple. The author locates and studies these paintings, all of them of artistic interest, since they are by major 17th-century painters such as Luca Giordano, Murillo or Pedro Orrente, as well as $16^{\text {th }}$-century masters such as Andrea del Sarto or Gerolamo Muziano.

Key words: Jesuits; Main House (Casa Profesa); Madrid; Painting; Architecture; $17^{\text {th }} \& 18^{\text {th }}$ centuries

La Compañía de Jesús creó las Casas Profesas para que en ellas habitasen los profesos. La denominación fue dada por San Ignacio de Loyola que no las quiso llamar con el nombre común de conventos (propio de los domicilios de las órdenes mendicantes) sino con el nombre usado por los clérigos regulares. La primera que se creó fue la de Roma, fundada por el propio san Ignacio en 1540, y en los años posteriores se sucedieron las fundaciones de otras en diversos países. En 
España la pionera fue creada por San Francisco de Borja en 1566 en Toledo. A esta le siguieron las de Valladolid (1567) y Burgos (1570) ${ }^{1}$.

La fundación de la Casa Profesa de Madrid se debe al deseo expreso del duque de Lerma, Francisco Gómez Sandoval y Rojas, valido del rey Felipe III. El duque era nieto por parte de su madre, Isabel de Borja, de San Francisco de Borja, tercer general de la Compañía de Jesús. Al parecer, la causa de la fundación de la Casa Profesa fue un milagro obrado por su santo abuelo. Según cuenta la tradición, en 1607, cuando la esposa de su hijo Cristóbal, Isabel de Padilla, iba a dar a luz, tuvo algunos problemas en el parto; el duque encomendó entonces su salvación a una reliquia del santo que él poseía y gracias a ello su nuera sanó 2 . Parece que fue en ese momento cuando el duque decidió la creación de una Casa Profesa dedicada al santo varón. La historia aunque pintoresca parece verosímil; sin embargo, sabemos que fueron otros los motivos reales por los que el valido de Felipe III decidió fundar esta Casa Profesa. En efecto, la decisión de crearla fue motivada por el deseo de erigir un lugar digno para el enterramiento de su abuelo, Francisco de Borja, que todavía no había sido ni beatificado. Para fundar esta institución cursó al General de la Compañía, Mucio Viteleschi, la solicitud de la creación de una Casa Profesa en Madrid así como la devolución del cuerpo de San Francisco de Borja que se encontraba en la Casa Profesa de Roma. Ambas peticiones fueron concedidas 3 .

Para la ubicación de esta Casa se pensó en un primer momento en la Parroquia de San Salvador de la capital por ser de pocos parroquianos, a lo que se negó el clero de la villa. Esto hizo que el duque sopesase la posibilidad de llevarla a Lerma pero lo desechó por la lejanía de la población vallisoletana de la Corte ${ }^{4}$. Finalmente, el duque hará donación de unas casas que poseía en la calle del Prado para que en ella residiesen los profesos jesuitas. Allí se trasladó el cuerpo del Santo y fue colocado el 18 de diciembre de 1617. Al acto acudieron, además del duque

\footnotetext{
${ }^{1}$ Sobre las Casas Profesas de la Compañía de Jesús ver C. O’NeILl, J. Mª Domínguez, Diccionario Histórico de la Compañía de Jesús, Tomo I, Madrid, 2001 (vid. vocem).

2 L. Coloma, Historia de las Sagradas reliquias de San Francisco de Borja, Obras Completas, Tomo XII, 1941, Madrid, p. 9.

${ }^{3}$ Son muy escasos los documentos que se conservan sobre la Casa Profesa de Madrid lo que hace muy difícil que podamos conocer como era su aspecto e información sobre lo que la decoraba. El acta de fundación de la Casa Profesa se encuentra en el Archivo de Protocolos de Madrid, Prot. 2662, fol. 35-44. Sobre la Fundación e historia de la Casa Profesa de Madrid en el Archivo Histórico Nacional de Madrid (en adelante AHN) se conservan dos documentos realizados en 1769 con motivo de la expulsión de los Jesuitas de España para poder controlar las fundaciones y memorias que pertenecían a esta Casa Profesa en los que se recoge alguna información sobre la institución jesuita. Los documentos son: Libro Maestro en que se expresa la Erección de lo que fue Casa Profesa de los Regulartes extinguidos de la Compañía de Jesús oy Real Congregación de Presbiteros Seculares dl Oratorio de San Felipe Neri con expresión individual de las rentas que pertenecieron a la Fábrica y Enfermería y de las Pias Memorias Mayores y menores fundadas por los fieles, así, en la Iglesia principal, como en la Capilla de la Virgen del Socorro y la Bóveda de Nuestra Señora de la Natividad; de los papeles que tiene cada una de las Fundaciones y rentas actuales. Formado de orden del $S^{r} D^{n}$. Marcos Felipe de Argaiz Caballero pensionado de la Real Distinguida Orden de Carlos Tercero, del Consejo de S. M. en el Supremo de Castilla y Juez Protector de las Expresadas Memorias. Por Dn. Juan Manuel del Val Contador y Archivero de la Comisión. (AHN, Secc. Clero, Jesuitas, Libro 341) y la Copia del Informe que dio $D^{n}$ Agustín de Leiza Erasso hecho al consejo sobre el extranamiento de los regulares de la Casa Profesa de esta Corte y ocupación de sus temporales con remisión a lo que resulta de los Autos y demas papeles Papeles que se han remitido (AHN, Secc. Clero, Jesuitas, Leg. 717). Existe otro documento que narra la Fundación y traslado de la Casa Profesa a la Plazuela de Herradores (AHN, Seecc. Clero, Jesuitas, Libro 719). Finalmente dentro del mismo proceso para finiquitar las fundaciones y memorias de la Casa Profesa existe otro documento más que no hace sino repetir en mayor o menor medida la información aportada por los documentos citados: Fundación de la Casa de los regulares de la Compañía, con título de Profesa calle del Prado y su traslación a la Plazuela de Herradores (AHN, Secc. Clero, Jesuitas, Leg. 717).

4 J. QuintanA, A la Muy Antigua, noble y coronada Villa de Madrid. Historia de su Antigüedad, Nobleza y Grandeza, Madrid, 1629 (Edic. Facsímil en 1980), T. II, libro 3º, p. 439-441.
} 
de Lerma y su familia, el Cardenal Zapata, que había traído el cuerpo de San Francisco de Borja desde Roma, el rey Felipe III, acompañado de los príncipes y la reina, así como de su hermano el Infante y toda una corte de nobles que honraron con su presencia la fundación de tan importante lugar.

En el momento de la fundación el mismo duque se "obligaba y obliga a edificar la iglesia y sacristía en la forma dicha y edificar también la cassa con sus fundamentos conforme a la planta que para ello se hiziese con habitación compuesta por cinquenta religiosos con sus oficinas comunes de refetorio, despensa y cocina, librería y con los aparatos que pareciere conviniente para huéspedes y enfermos y todo lo demás. En orden a lo qual desde luego hacía donación a la dha Cassa Profesa de las cosas y Sitio que tiene comprado en la Calle del Prado juntamente con las escripturas de Compra, y de lo que está allá edificado y de lo que adelante se comprase y edificase para la dicha Ygl y habitación. Ansimismo se obligó su Ex ${ }^{a}$ de adornar la Iglesia de retablos; Imagen, Plata y ornamentos convinientes a la grandeza del templo y numero de altares del, y de proveer la casa de todas las alajas que los religiosos de la Compañía suelen usar en sus zeldas y en las oficinas comunes y de proveer de libros la librería común y dos celdas para dos predicadores". Para ello el duque "en orden a lo sobredicho desde luego su excelencia haze donación a la dicha cassa de la plata, Relicarios ymagenes, ornamentos que les tiene dados y de lo que adelante les diese asta poner esta obra en su perfección lo qual aunque su excelencia desea empezalla y acanalla en sus días en la forma que se dize en este capitulo y el prezedente y assi lo suplicamos todos a la divina Majestad. Pero en casso que esto no fuese así se obliga a dejar bastante hazienda con que se haga". Del mismo modo don Francisco de Rojas y Sandoval señalaba que era su voluntad que se debía llamar "Casa Profesa de la Compañía de Jesús, sin tener abdicación de otro ningún Santo, pero si su Santidad o los Summos Pontífices sus sucesores alenten la santidad del Beato Padre Francisco de Borja le canonizen por santo, con lo que se le podría edificar templo y dedicar altares la iglesia de la dicha Casa Profesa y la misma casa se han de llamar e intitular y se llama e intitula Sant Framcisco de Borja"5.

Una de las condiciones que el duque puso a la Compañía de Jesús fue que no moviesen de dicho sitio el cuerpo del santo pues si así sucediese lo perderían y se llevaría al Colegio de Gandía ${ }^{6}$. Sin embargo los jesuitas pronto se cansaron de este emplazamiento que consideraban demasiado apartado del centro de la ciudad y fuera de los lugares de tránsito e influencia y, tal y como cuentan las crónicas, tras tener el permiso de los patronos de la fundación y por medio de algunas artimañas, se trasladaron el 10 de mayo de 1627, con nocturnidad y alevosía, a un nuevo establecimiento en la plazuela de Herradores 7 . Su ubicación exacta estaba en la manzana creada por las calles de Bordadores, Mayor, Hileras y su entrada daba a la dicha plaza de Herradores ${ }^{8}$.

Desconocemos por completo cómo era la Casa Profesa y su templo. Sabemos que en su altar mayor estaba enterrado San francisco de Borja, y que "por el primor de su estuco o escaiola su

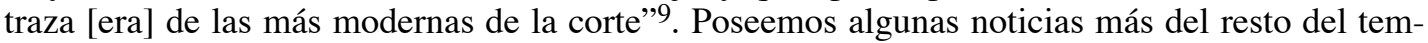
plo que estaba adornado con altares y otras reliquias ${ }^{10}$

5 AHN, Secc. Clero, Jesuitas, Libro 719. Fundación de la Casa Profesa. AHPM, prot. 2662, fol. 36 vº.

6 Ídem, fol. 37 vo.

7 AHN, secc. Clero, Jesuitas, leg. 712. Casa Profesa de Madrid. Fundación de la Casa de los Regulares de la Compañía, con el título de Profesa, calle del Prado y su traslación en la Plazuela de Herradores, $\mathrm{f}^{\mathrm{0}} 3 \mathrm{v}^{\mathrm{o}}$.

$8 \mathrm{AHN}$, Secc. Clero, Jesuitas, Leg $712^{3}$. Estracto y Puntual razón de los resultados de los títulos de pertenencia de la casa que comprende el sitio de la Iglesia y casa que tenían y poseían los regulares de la Compañía de Jesús

9 AHN, Secc. Clero, Jesuitas, leg. 717, Copia del Informe... (s/n).

10 Sabemos que antes de 1629 se veneraba en el altar mayor una imagen de mármol de Nuestra Señora realizada en Nápoles y un Santo Cristo en el sepulcro realizado en talla. (J. QuintanA, A la Muy Antigua..., p. 441) 
El fin de la Casa Profesa se produce con la expulsión de los jesuitas de España el $1^{\circ}$ de abril de 1767, por Real Orden de Carlos III ${ }^{11}$. El edificio quedo vació hasta el 13 de enero de 1769 en que el rey lo cede a la real Congregación del Oratorio de San Felipe Neri para que ubicasen en él su sede. Esto se hizo cediéndoles los retablos de las capillas y altar mayor. Sin embargo se decidió que los adornos móviles podrían servir para adornar otras iglesias pobres ${ }^{12}$. Allí permaneció la Congregación hasta la exclaustración de los regulares de 1836. Desafortunadamente el templo y la Casa Profesa fueron derribados en el s. XIX y sobre su solar se edificó una galería de cristales con mercado, destruido ya en este siglo donde se abrió la actual calle de san Felipe Neri ${ }^{13}$.

Nada más entrar a vivir en ella los oratorianos de san Felipe, el rey Carlos III aprovechó rápidamente para, nada más entregar el templo y Casa Profesa, intentar adquirir algunas de las valiosas obras que en ella se encontraban. Para ello envió a su Primer Pintor de Cámara, Antonio Rafael Mengs, a que viese las obras que allí se conservaban y seleccionase y tasase las más importantes para su adquisición. Recordemos que en estos años fue frecuente esta actividad de coleccionista de Carlos III que no hace sino continuar la pasión de sus padres. En realidad podemos explicar este interés por la adquisición de obras debido a la necesidad de conseguir cuadros para decorar el nuevo Palacio Real de Madrid. A causa de esto, en 1764, asesorado también por el pintor bohemio, compra algunas obras provenientes de la colección de Juan Kelly ${ }^{14}$. De nuevo en 1768 adquirió 30 pinturas provenientes de la colección del marqués de la Ensenada, en la que también utilizó a Mengs como evaluador y tasador de las obras ${ }^{15}$.

Hasta ahora solo teníamos noticia de la respuesta dada por el bohemio a la orden del rey, fechada el 2 de febrero de 1769. En ella recomendaba la compra de varias pinturas pues eran "las de más estimación y dignas de que las tenga S. M.”, lo que se hizo en esa misma fecha ${ }^{16}$. Nada sabíamos de las obras que había seleccionado Mengs, ni de las que se habían adquirido. Hoy podemos conocer qué obras fueron las seleccionadas y después adquiridas por Carlos III. En el Archivo General de Palacio se conserva un documento con la tasación y selección de estas obras, así como la factura de la compra de las pinturas de la extinta Casa Profesa que Carlos III realizó ${ }^{17}$.

${ }^{11}$ Sobre la expulsión de los Jesuitas de España véanse M. Danvila y Collado, El Reinado de Carlos III, vol. III, Madrid, 1890-1896; C. Eguía RuIZ, Los jesuitas y el motín de Esquilache, Madrid, 1947; M. Batllori, La Cultura hispano-italiana de los jesuitas expulsos. Españoles-hispanoamericanos-filipinos, 1767-1814, Madrid, 1966 y el estudio introductorio de J. CEJUdo y T. EGIDo a la obra de Pedro Rodríguez de Campomanes, Dictamen fiscal de expulsión de los jesuitas de España (1766-1767), Madrid, 1977, p. 5-40.

12 AHN, Secc. Clero, Jesuitas, leg. 717, Copia del Informe... Curiosamente se excluyen algunas obras del Camarín de San Francisco de Borja que debían subsistir allí por deseo expreso de los patronos.

13 P. RÉPIDE, Las calles de Madrid, Madrid, 1999, p. 625.

14 M. Águeda Villar, "Una colección de Pinturas comprada por Carlos III", IV Jornadas de Arte. El Arte en Tiempos de Carlos III, Madrid, 1989, p. 287-295.

15 El documento de la compra se encontraba en el Archivo Histórico Nacional y fue publicado por León TeLLO y M$^{\mathrm{a}}$. V. Sanz Sanz, Tratados neoclásicos españoles de Pintura y Escultura, Madrid, 1980, p. 464. Un estudio más completo sobre las obras compradas por Carlos III y su localización hoy en día en M. ÁGUEDA VILLAR, "Una colección de pinturas en el Madrid del siglo XVIII: El Marqués de la Ensenada", Cinco siglos de Arte en Madrid (XV-XX), III Jornadas de Arte, Madrid, 1991, p. 165-177.

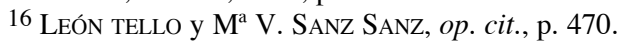

17 AGP, Secc. Carlos III, Cámara, leg. 88. "Valuación de las Pinturas que por Dn Antonio Rafael Mengs se ha ejecutado de las que por el mismo se reconocieron en virtud de $R^{l}$ orn en 15 de enero del corriente, como dignas de particular aprecio, entre todas las qe existían y subsisten a orn de S. M. en la Iglesia, Sacristía y demás oficinas de la R. ${ }^{l}$ Congregación del Oratorio de $S^{n}$ Phelipe Neri, $q^{e}$ anteriormente se denominó Casa Profesa.

Sachristía maior

- Quatro Quadros originales de Lucas Jordan, apaisados qe se encontraron en la Sacristía principal, su altura dos varas y media cada uno, y de largo quatro y media qe representan, una la huida a Egipto, otro el Nacimiento, otro la 
La adquisición de las obras fue muy rápida pues la fecha de tasación de las obras es del 15 de enero, solo dos días después de la ocupación del edificio por los regulares del oratorio de San Felipe Neri. El 2 de febrero ya estaban pagadas las pinturas que pasaron a las colecciones reales. Gracias a este documento podemos conocer una importante parte de la decoración que poseía la Casa Profesa así como identificar las obras, lo que servirá para aclarar el origen de algunas pinturas que pertenecían a las colecciones reales.

Comenzaremos el estudio por las pinturas que se encontraban en la Sacristía Mayor de la Casa Profesa. En ella se encontraban las que, sin duda, podemos considerar como las más importantes. Me refiero a la serie de cuatro cuadros de Lucas Jordán que representan: "uno la huida a Egipto, otro el nacimiento, otro la sagrada familia y ultimo Jesús, María y Jph. en Camino"18. Los cuadros pasaron directamente al Palacio Real de Madrid como lo demuestra el inventario de 1772 en el que se describen con algo más de detalle. En este aparecen ubicados en la Pieza de Comer de la Serenísima Infanta: "Profesa. Quatro quadros iguales de la $H^{a}$ de Nra $S^{r a}$. Que son: Nacimiento; huida a Egipto en una barca; Jesús, María y José

Sagrada familia y ultimo jesús, María y Jph. en camino, su valor uno con otro a seis mil $r^{s}$ que componen los quatro veinte y quatro mil $r^{s} .24000$.

- Otro Quadro en la misma Sacristía de varaa y tercia, y alto, y una vara escasa de ancho qe representa nra Sra. Con el Niño Jesús, original de murillo, que regula en dos mil y quatrocientos $r^{s}$. $V^{n}$. 2400.

- Otro Quadro en el citado parage de vara y dos tercias de alto, y vara, y tercia de ancho, copiado del original de Rafael de Urbina, representa la Virgen con el Niño Jesús, Sta Isabel, $S^{n}$ Juan y $S^{n}$ Jph. de lexos, le tasa y regula en dos mil reales $v^{n}$. 2000.

Camarín de $\underline{\underline{n}} \underline{\text {. Fran }} \stackrel{\text { co }}{\text {. De Borja. }}$.

- Un Quadro en tabla de una vara de ancho, y quatro pies escasos de alto de mano de Andrés del Sarto, encontrado en el Camarín de $S^{n}$. Fran ${ }^{c o}$. de Borja, qe representa nra $S^{r a}$ con el Niño Jesús, y otras dos cabezas, que le tasa y regula en tres mil $r^{s}$. $V^{n} .3000$

- Un país de lámina de catorce dedos de alto y diez de ancho, encontrado en dho. Camarín, Pintado de Brugl, el que tasa en ochocientos $r^{s}$. $v^{n} .800$.

- Un Quadro de quatro pies escasos de alto, y dos varas y ocho dedos de ancho qe representa el Nacimiento de nro. $S^{o r}$. de la Escuela Lombarda, encontrado en dho. Camarín, le valua en mil reales $v^{n} .1000$.

- Otro quadro de cinco pies y medio escasos de alto y quatro pies y dos dedos de ancho, que representa la Coronación de Espinas de nro. Sor del título o estilo de Muciano, que se hallaba en dho Sitio, vale seiscientos $r^{s}$. $v^{n} .600$.

$D^{n}$ Agustín de Sanz Contador de Resultas de S. M. y Contralor Gral de su $R^{l}$ Casa, Capilla y Cámara.

Por $R^{l}$. orn. Comunicada por el Ilt ${ }^{m o}$. Sor. $D^{n}$. Miguel de Muzquiz $S^{r i o}$. De Estado y del Despacho Universal de Hacienda, al Ex. ${ }^{\text {mo }}$ S. or Marq. de Montealegre Mayordomo Mayor de la $R^{l}$. Casa, en 2 de Febrero proximo antecedente; pasada a la oficina de mi cargo consta haver consignado el Rey $33800 r^{s}$. de $v^{n}$. Para satisfacer el importe de diez. Pinturas que para su $R^{l}$. Servicio, havia elegido y tasado $D^{n}$ Antonio Rafael Mens primer Pintor de Cámara de S. M. de las que existían en la Sacristía Mayor y Camarín de $S^{n}$. Franco. De Borja de la Casa Profesa que fue de los Regulares de la Compañía; y los expresados $33800 r^{s}$. se deven entregar por la tesorería Mayor al Sor. Dn. Agustín de Leyza Eraso del Consejo de S. M. en el $R^{l}$. y Supremo de Castilla y Juez comisionado $p^{a}$. la ocupación de temporalidades de la enunciada Casa Profesa, en vrd de su recibo, y de este instrumento de que ha de tomar la razon el $S^{\circ}$. $D^{n}$. Joseph de Guzmán, Grefier gral de la $R^{l}$. Casa, Capilla y Camara, conforme a la ultima $R^{l}$. resolución. Aranjuez, 11 de abril de 1769

Real Cassa de S. M.. 11 de Abril de 1769.

Libranza de $33800 r^{s} . v^{n}$. Librados en tesorería mayor del importe de 10 pinturas compradas de orn de S. M. y existían en la Sacristía y Camarín de $S^{n}$ Fran $^{c o}$. De Borja en la Casa profesa de los regulares de la Compañía.

El recibo de Mens original se halla con la $R^{l}$. orden."

18 AHN, leg. 88, vid nota supra. 
caminando, y Nra sa con el niño y $S^{n}$ Juan que juegan con un cordero, en el que ay sta Isabel y $s^{n}$ Joachin" 19.

Los cuadros permanecieron juntos al menos hasta el final de la guerra de la Independencia ${ }^{20}$. En el s. XIX ya no aparecen como una serie y se pierde su rastro.

No he conseguido identificar todos los cuadros de Giordano por lo que el resultado de su localización ha sido solo parcial. Gracias al catálogo de la exposición dedicada a la presencia de Giordano en España, comisariada por el profesor Pérez Sánchez, en el que se realizó un catálogo de sus obras en las colecciones de Patrimonio Nacional, hemos podido localizar dos obras de la serie ${ }^{21}$.

La primera de ellas sería la Huida a Egipto, que se encuentra actualmente en el Palacio Real de Aranjuez $^{22}$ (Fig. 1). Por sus dimensiones ${ }^{23}$ y tema se la puede identificar, sin duda alguna, con "Huida a Egipto en una barca" que aparece en la ya citada relación de Mengs. La obra aparece firmada: "Jordanus F.". De las cuatro pinturas era la única que se encontraba en el Palacio Real de Madrid en 1870 como demuestra el inventario que se hizo en ese año ${ }^{24}$. En ella vemos cómo la Sagrada Familia es transportada en una barca que es guiada por ángeles. El tema no es original en la producción de Giordano pues existen otras pinturas con una representación muy parecida si bien es esta obra la que trata el tema con un mayor desarrollo escénico y una mayor monumentalidad 25 . Una de las más interesantes es la que se conserva en el Museo de la Academia de Bellas Artes de San Fernando que repite la misma iconografía en un tamaño más reducido. Tal vez se trate de un boceto preparatorio o de una copia de un discípulo que seguiría el modelo de la Casa Profesa ${ }^{26}$.

El otro cuadro de la serie que hemos podido identificar con una de las obras compradas por Carlos III a los jesuitas fue también publicada por primera vez en la exposición de Madrid. Se trata de la

19 AGP, Administrativo, leg. 38, fol. 19. Aparecen de nuevo inventariados a la muerte de Carlos III en la Pieza amarilla del Palacio Real: "Quatro de quatro varas y media de largo y dos y media de ancho: El primero el Nacimiento: Segundo la huida a Egipto; tercero Jesús, Maria y Josef en una barca y el quarto el niño Jesús y $S^{n}$ Juan que juegan con el cordero a ocho mil reales cada uno...32000", (Inventarios Reales. Carlos III, 1788-89, t. I, Madrid, 1988, p. 56, n 525).

${ }^{20}$ En el Inventario del Palacio Real de 1794 se encontraban aún juntos en la Pieza Amarilla a la izquierda y se habían revalorizado hasta 32000 reales (consultado el inventario transcrito en la Biblioteca del Museo del Prado). En el Inventario de 1814 del Palacio Real de Madrid aparecen separados. Dos en la Pieza Amarilla: "Dos de quatro varas de largo, dos y media de alto, la huida a Egipto cuando se embarca; Sagrada familia y San Juan. Jordán" y otros dos en la Pieza Primera: "Dos de quatro varas de largo dos y media de alto, El Nacimiento; La huida a Egipto. Jordán”. En el inventario de 1834 aparece la serie dividida en el Palacio Real en la tercera pieza de papel se encontraban "Dos apaisados originales de Jordán asuntos de Huida de Egipto, alto ocho pies y quarto, largo doce pies que valen con sus marcos dorados a seis mil quinientos reales cada uno" (AGP. Inventario de 1834, f. 3). Los otros dos podrían ser los que se encontraban en la Pieza de los Porteros de Cámara: (f. 5 $v^{o}$ ) "Cuatro cuadros originales de Jordán de Historia Sagrada y dos romana apaisados, alto diez pies por doce de ancho; vale cada uno con su marco a diez mil setecientos ochenta reales cada uno". Me refiero claro está a los de Historia Sagrada.

${ }^{21}$ Luca Giordano y España, Palacio Real de Madrid, cat. exp. a cargo de A. E. PéREz SÁnchez, Madrid, 2002.

22 Op. cit, p. 308, R. 131. Inv. Patrimonio Nacional: $\left.\mathrm{n}^{\circ} 10022664\right)$.

23 Sus medidas son $205 \times 365 \mathrm{~cm}$., muy aproximadas a las dos varas y media de alto por cuatro y media de ancho $(210 \times 375 \mathrm{~cm}$.$) .$

24 J. J. LunA, "Inventario de las Pinturas del Palacio Real de Madrid en 1870 y Actas de Corrección del mismo Inventario en 1873", Boletín de la Real academia de la Historia, CLXXI, cuaderno II, p.378.

Pieza $\mathrm{n}^{\circ}$ 63. "19/7801. Un cuadro en lienzo, pintado al óleo, marco dorado ancho tres metros treinta y tres centímetros; alto dos metros cinco centímetros. San José La Virgen y el Niño en una barca guiada por ángeles, prontos a desembarcar en tierra. Por Jordán".

25 De la misma época es la Huida a Egipto en una barca (Col. Morandori, Roma) fechada hacia 1682. Su composición es muy parecida si bien las dimensiones son menores y la posición de las figuras y la barca, guiada aquí por un joven, están dispuestas a la inversa (O. Ferrari; F. ScAvizZI, Luca Giordano, Milán, 1992, vol. I, p. 305, A319, vol. II, p. 639, lám. 427). Sin duda debe tratarse de una versión más antigua del tema.

${ }^{26}$ La obra se encuentra en los almacenes de la institución. Sus medidas son 57 x $100 \mathrm{~cm}$. Pérez Sánchez lo consideraba obra de un discípulo de Giordano (A. E. Pérez SÁnCHEZ, "Inventario de las pinturas de la Real Academia de Bellas Artes de San Fernando", Academia, 1964, n 18-19, p. 58, n 620). 


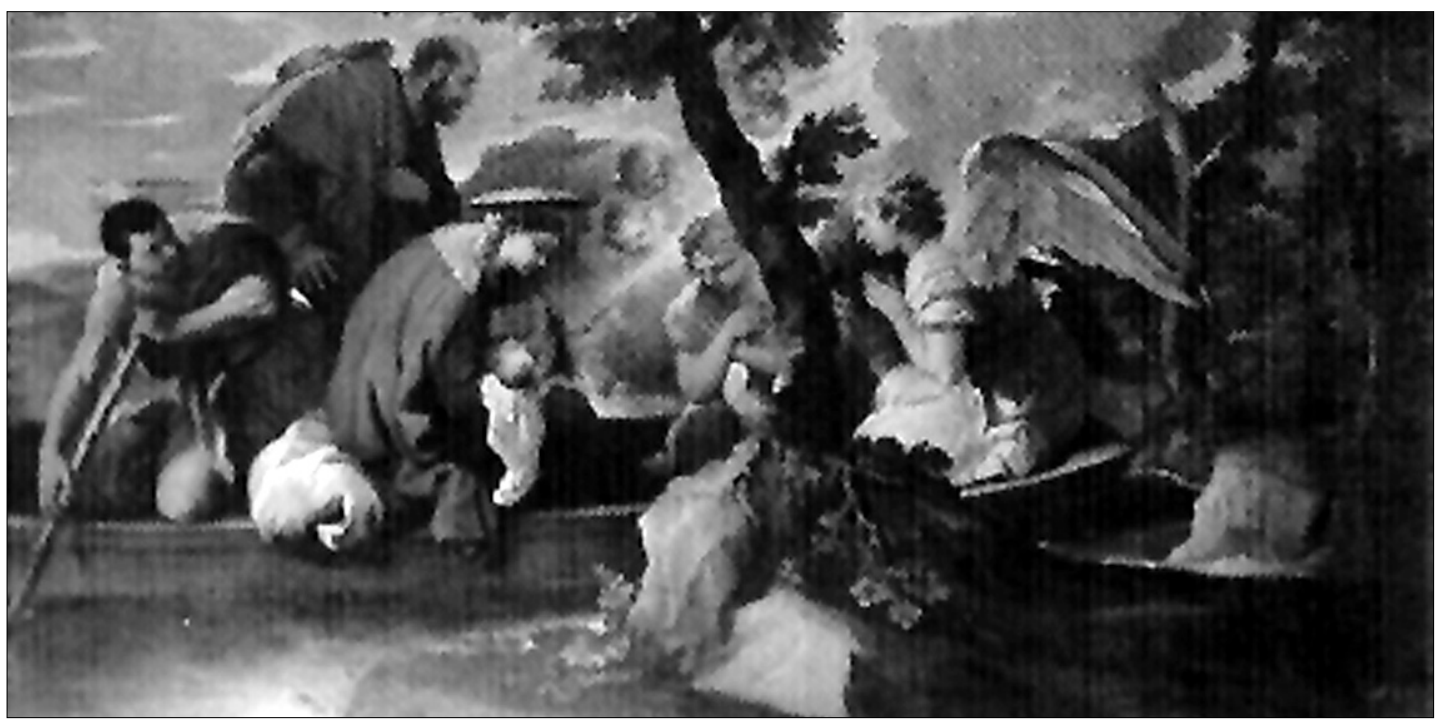

Fig. 1. Luca Giordano. Huida a Egipto.

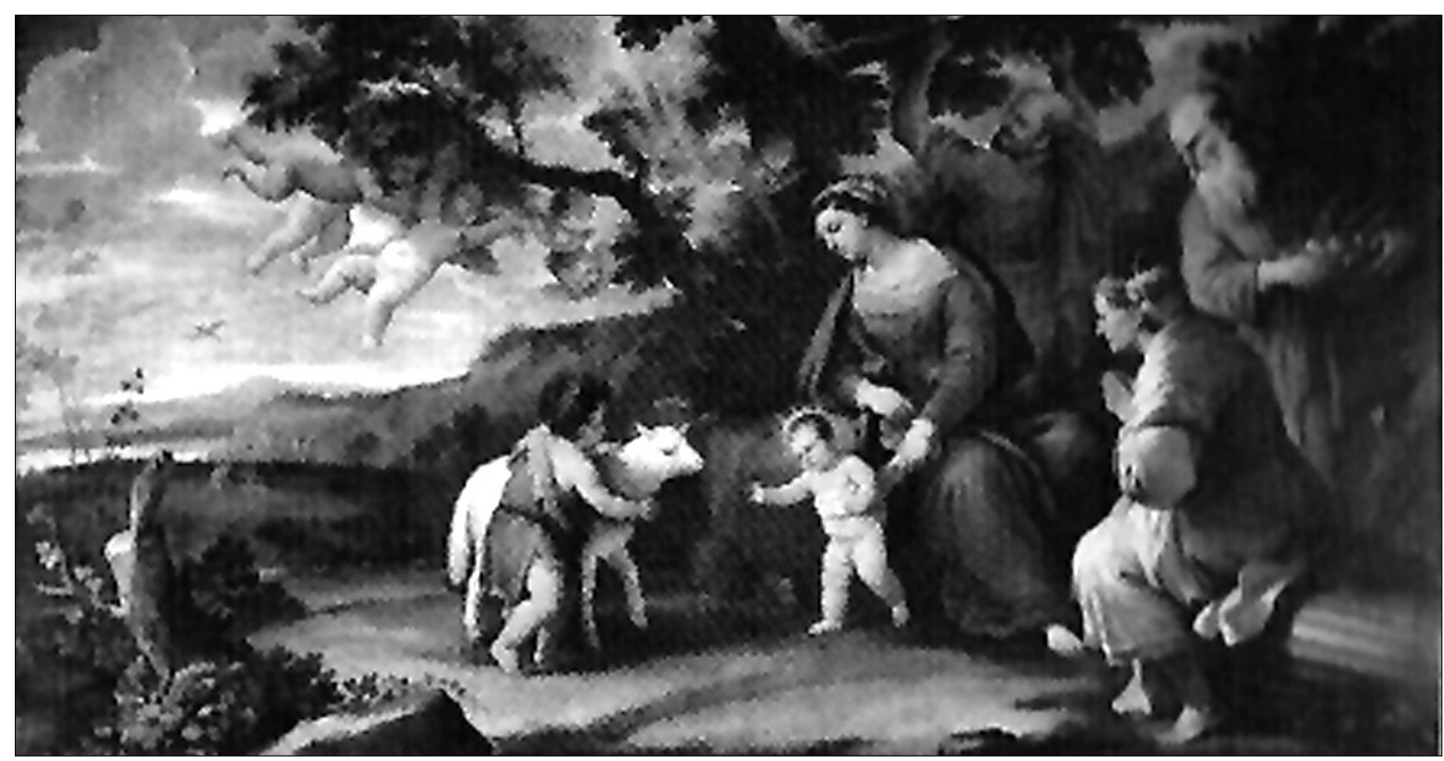

Fig. 2. Luca Giordano. Sagrada Familia con San Juanito, Santa Isabel y San Zacarías.

Sagrada Familia en un paisaje con Santa Isabel, San Zacarías y San Juanito (Fig. 2), (198 x 361, Palacio Real de Madrid, firmado: "Jordanus" ${ }^{27}$ y que sin duda alguna debe relacionarse con la descrita como la "Sagrada Familia" de la relación de Mengs. La identificación es clara si recordamos la descripción del Inventario de 1772, no solo por las medidas sino también por los personajes descritos ${ }^{28}$.

27 Luca Giordano y España, op. cit, p. 309, R. 133 (Inventario Patrimonio Nacional: $\mathrm{n}^{\circ}$ 10063375).

28 vid. Nota 17. 
Sin duda se trata de una obra de una gran originalidad en cuanto al tema representado, que es único en la producción de Jordán. Se trata del Encuentro de la Sagrada Familia con San Juanito, Santa Isabel y San Zacarías a su vuelta de Egipto, tema sacado de los evangelios apócrifos y que pertenece al ciclo de la infancia de Cristo cuya representación se produjo especialmente en Italia ${ }^{29}$.

Mayor dificultad he encontrado a la hora de identificar los otros dos cuadros de la serie. Serían los que representan El Nacimiento y Jesús, María y José en camino o caminando. Por el tamaño no he podido localizar entre toda la obra de Giordano ningún cuadro que se aproxime a las medidas de estos y en los que el tema representado sea semejante. En las colecciones del Patrimonio Nacional se conserva un lienzo que representa la Huida a Egipto (actualmente en el Palacio Real del Pardo, $\mathrm{n}^{\mathrm{o}}$ inv: 10073785$)^{30}$, muy próximo al tema que podría representar el lienzo Jesús, María y José en Camino. En el lienzo se ve a San José y a la Virgen con el niño en brazos que en su huida a Egipto se dirigen andando a una barca en la que ya ha sido embarcado el asno. Su formato apaisado y la firma, que es similar a los anteriores ("Jordanus"), nos podrían hacer pensar que estuviese relacionado con la serie, si bien el tamaño es bastante inferior a los anteriores, (121 x 228). Posiblemente debemos suponer que era una de las obras adquiridas por Carlos II que fueron enviadas en $1788^{31}$.

Más complicada es la localización de la otra obra que se citaba como el Nacimiento. Realmente no sabemos qué representaría, si solamente el nacimiento o si estaría unido a alguna de las adoraciones. Ninguna obra del Patrimonio Nacional ni del Museo del Prado puede relacionarse con este cuadro ${ }^{32}$. Ni siquiera entre las obras publicadas por Ferrari y Scavizzi se encuentra alguna obra que se pueda identificar o relacionar con esta ${ }^{33}$.

Las obras identificadas han sido datadas hacia $1700^{34}$ si bien debemos adelantar esta fecha pues según parece estas obras fueron realizadas por Luca Giordano antes de su venida a España pues como tales las recoge Palomino en su Museo Pictórico. El pintor, al enumerar las pinturas del napolitano que se encontraba en España, se detiene en las existentes en la Casa Profesa, de las que dice se encontraban antes de la venida del napolitano a nuestro país: "Y cuatro lienzos apaisados de la vida de la virgen en la Sacristía de la Casa Profesa de esta Corte" ${ }^{35}$, por lo tanto la obra debió ser realizada hacia 1680-1692.

29 La historia procede del evangelio apócrifo del Pseudo Buenaventura si bien la historia narra como al que se encuentra la Sagrada Familia al volver de Egipto es a San Juan niño que les espera con frutos silvestre, para después ir todos juntos a ver a Santa Isabel (L., REAU, Iconografía del Arte Cristiano, Iconografía de la Biblia. Nuevo Testamento, tomo 1, vol. 2, Barcelona, 1996, p. 298).

30 Ídem, p. 309, R. 132. También lo recogen O. Ferrari; G. ScAvizzi, Luca Giordano, Nápoles, 1992, p., nº A685.

31 E. GonZÁlez AsEnJo, "Envíos de pinturas de Giordano a España en 1688" en Luca Giordano y España, 2002, p. 81. La pintura se encontraba en el Palacio Real de Madrid en 1873: "Pieza núm. 62. "17/7769. Un cuadro en lienzo al óleo marco dorado apaisado; ancho dos metros treinta centímetros; alto un metro diez y ocho centímetros. Representa "La huida a Egipto" con varios ángeles y figuras que acompañan a la virgen con el niño y San José que va a entrar en una barca. Firmado "Jordans". (Luna, op. cit., 1974, p. 377).

32 En Patrimonio Nacional se encuentra una Adoración de los Reyes Magos ( ${ }^{\circ}$ Inv. 10014632) pero sus medidas (142 x 205) quedan bastante lejos de las que debería tener.

33 En la colección Almazán de Madrid se conserva una Adoración de los Pastores con un formato parecido. La obra se relaciona por estilo con las de Guadalupe por lo que se fecha hacia 1696 por lo tanto posterior a la de la serie que aquí estudiamos. Desconocemos las medidas, pero sirve muy bien para hacernos una idea de cómo podría ser la pintura de la Casa Profesa (Ferrari/Scavizzi, 1992, vol. I, p. 342, A581; vol. II, p. 772, lám. 728). Si se tratase de una representación en la que solo apareciese el nacimiento la pintura con este tema que se encontraba en 1992 en el mercado anticuario londinense, El Nacimiento, podría ser un buen ejemplo del tipo de composición y representación que podía tener la pintura adquirida por Carlos III. Con un formato apaisado pero menores medidas (152 x 281), Ferrari y Scavizzi la datan hacia 1682 por lo que estaría muy cercana en el tiempo (Ferrari/Scavizzi, op. cit, vol. I, p. 309, A346; vol. II, ám. 452).

${ }^{34}$ Luca Giordano y España, op. cit, p. 309.

35 A. Palomino, Vidas, Madrid, 1724 (Edic. N. Ayala Mallory, 1986), p. 366. 
Como ya hemos indicado el conjunto se encontraba en la Sacristía Mayor de la Casa Profesa. Desconocemos el origen de las pinturas que, por el tamaño y su concepción como una serie, debieron tratarse de un encargo preciso y programado de los jesuitas dedicado a la Virgen ${ }^{36}$. Sin duda se trataba de uno de los conjuntos decorativos en lienzo más importantes de Madrid realizado por el artista napolitano antes de su venida a España y así será señalado no solo por Palomino sino por aquellos que escribieron sobre las obras artísticas que se encontraban en la capital ${ }^{37}$.

Para terminar con la serie de Giordano solo me cabe señalar el alto precio en el que fueron tasadas. Algo frecuente como se ha visto en otras compras efectuadas por Carlos III. Esto demuestra el interés que todavía suscitaba la obra del napolitano cuyas pinturas gozaban de una alta valoración a fines del siglo XVIII.

Entre las obras situadas en la Sacristía de la Casa Profesa, Carlos III adquirió, junto con los cuadros de Jordán, la obra de Murillo Virgen del Rosario con el niño ${ }^{38}$. Es posible que fuese muy del gusto del soberano pues la pintura pasó a sus aposentos como lo indica el inventario de 1772, en el que el cuadro aparece en la antecámara de S. M., donde se describe de una manera más completa, sin olvidar el origen de la pintura: "Profesa. Otra de nra. S $^{\text {ra }}$ con el niño, que tienen un rosario en la mano, sentada y el niño en pie sobre sus rodillas, de más de medio cuerpo"39.

La localización de la pintura es bastante difícil pues ninguna obra en España concuerda exactamente con la que tenemos documentada. Si seguimos la descripción descubrimos que es una imagen de devoción que será representada numerosas veces por el pintor sevillano. La primera imagen que nos viene a la mente es la conservada en el Museo del Prado (cat. $n^{\circ}$ 975). Sin lugar a dudas una de las más bellas pinturas de Murillo, pero dudo que se pueda identificar con la pintura de la Casa Profesa. Si comparamos las medidas vemos que la del Museo del Prado mide 164 x $110 \mathrm{~cm}$ mientras que la nuestra vendría a medir aproximadamente 105 x 84 (vara y tercia de alto por vara escasa de ancho). Además, si atendemos a la descripción de Calleja descubrimos que dice como la Virgen está pintada "de más de medio cuerpo", mientras que la figura de María del cuadro del Museo del Prado está pintada de cuerpo entero con lo que debemos descartar la identificación con esta pintura.

Entre las colecciones de Patrimonio Nacional no hay ninguna pintura que se pueda identificar con la que ahora tratamos, tampoco en el Museo del Prado. Angulo Iñiguez quiso relacionar la obra comprada en la Casa Profesa con la existente en la Colección Wallace de Londres: Virgen del Rosario con el Niño (Fig. 3) (Inv.: P. 136) ${ }^{40}$, pues las medidas de ambas se asemejan bastante (109 x 80). También la representación se aproxima mucho a lo descrito en los inventarios pues la posición del niño, el rosario y la figura de la Virgen, de más de medio cuerpo, concuerdan con los datos que poseemos. El cuadro, tal como señala Angulo, fue considerado por Mayer como una copia o un original muy barrido, lo que hace que en la galería londinense esté atribuido,

\footnotetext{
36 En el Instituto jesuita Leone XIII de Milán existen dos pinturas de Giordano que representan la Huida a Egipto y la Adoración de los Pastores (o/l, 250 x 310). El tema de la huida a Egipto es muy similar al de Patrimonio Nacional y la Adoración de los Pastores podría relacionarse con el Nacimiento de la serie de la Casa Profesa. Sin duda Giordano debió realizar diversas series con la Infancia de Cristo como tema central, especialmente para el mundo jesuita. Están fechadas hacia 1675 (los cuadros aparecen publicados en Ferrari/Scavizzi, op. cit, no A251, a y b).

37 C. Bedat, "Un manuscrito del Escultor Don Felipe de Castro: ¿Esbozo inédito de una parte del "Viaje de España" de D. Antonio Ponz," Archivo Español de Arte, 1968, n 162-63, p. 215.

38 AGP, Carlos III, Cámara, leg. 88.

39 AGP, Administrativo, leg. 38. Pinturas del nuevo Real Palacio, 1772, Andrés de la Calleja, fol. 9vº . De nuevo aparece en el Inventario de 1788-89 en la Pieza de Paso que va a la librería (Inventarios Reales. Testamentaría de Carlos III, 1988, p. 32. Allí seguía en el inventario de 1794.

40 D. ANGUlo IÑIGUEZ, Murillo, 1981, p. 152, nº 153. Al parecer el cuadro fue adquirido en subasta pública en Londres en 1858 .
} 
con dudas, al maestro sevillano ${ }^{41}$. La hipótesis de la copia parece confirmada por la existencia de otra copia en Ámsterdam en la que la Virgen aparece de cuerpo entero, lo que hizo suponer a Angulo que había de existir un original del que vendrían estas dos copias ${ }^{42}$, si bien el historiador sevillano subraya la calidad de la obra de Londres. Tal vez el original fuese el existente en la Casa Profesa.

Como sucede con las obras de Jordán, desconocemos cuándo y por quién fue adquirida para la Casa Profesa. Su compra por parte de Carlos III no hace sino confirmar el interés que seguía despertando aún la obra del sevillano en la segunda mitad del s XVIII. Heredado el gusto por Murillo de su madre, Isabel de Farnesio, no era esta la única vez que Carlos III adquiría cuadros del pintor sevillano, pues al igual que sucedió con algunas obras de Giordano, adquirió obras de Murillo al marqués de la Ensenada y a Juan Kelly43.

Finalmente, entre las obras que se encontraban en la Sacristía Mayor de la Casa Profesa y que compró el rey, estaría una "copia de Rafael de la Sagrada Familia con San Juan y Santa Isabel" 44 . Por las medidas y su descripción parece tratarse de una copia de la Sagrada Familia de Rafael conocido como "La Perla" que se encuentra en el Museo del Prado de Madrid (144 x 115, ${ }^{\circ}$ cat.: 301 ). La obra debía estar en muy mal estado pues pasó directamente al estudio de Andrés de la Calleja para ser restaurada ${ }^{45}$. En el Inventario de 1772 aparece citada entre las obras que debían ser restauradas y una nota indica que todavía no lo había sido en 1785 a la muerte del pintor ${ }^{46}$.

Es muy difícil identificar esta obra entre las copias que existen de esta pintura en el Museo del Prado o en Patrimonio Nacional. En su mayoría proceden de El Escorial ya que este fue el lugar donde estuvo la pintura original y donde se realizaron numerosas copias que hoy se conservan en Patrimonio Nacional y que no creemos que se identifiquen con la pintura aquí tratada ${ }^{47}$. Sí podría relacionarse con la pintura que Ponz vio en el dormitorio del cuarto de la reina del Palacio Real que consideraba "una copia muy buena de Rafael de Urbino"48.

\footnotetext{
41 La información aparece en ANGULO IÑIGUEZ, op. cit.

42 Ídem, p. 153. Las medidas de la obra de Ámsterdam son 184 x 144 (lám. 534). La calidad de esta obra es muy inferior a la londinense.

43 Águeda Villar, 1991, op. cit, p. 175. No es el lugar de enumerar las obras de Murillo adquiridas por Carlos III al marqués de la Ensenada, debe recordarse que la adquirida en la Casa Profesa a pesar de su pequeño tamaño había adquirido un valor sumamente alto de 2400 reales.

44 En el documento del AGP aparece citado como: "de vara, y dos tercias de alto, y vara y tercia de ancho, copia de Rafael de Urbina, representa la Virgen con el Niño Jesús, Sta Isabel, $S^{n}$ Juan y $S^{n}$ Jph de lexos, le tasa y regula en dos mil reales". En el ya citado inventario de 1788-89 aparece de nuevo en el mismo sitio. No lo hace en el s. XIX por lo que pudo haber desaparecido a principios de siglo.

45 Ma L., Barrero Sevillano, "La Restauración de Pinturas de las Colecciones Reales durante el s. XVIII", Archivo Español de Arte, 1980, n 212, p. 485.

46 AGP, Carlos III, Administrativo, leg. 38, fol. 67v $\mathrm{v}^{\circ}$ La pintura pasó primero a Mengs y en 1777 a Andrés de la Calleja: "Una tabla que representa a Nra. Señora, el Niño, San Juan, y $S^{n}$ Joseph, de vara y quarta de alto, y vara escasa de ancho. Copia de Rafael". Sin embargo no podemos asegurar que sea esta la pintura pues las medidas son menores. Puede que se recortase en el taller de Calleja. Si bien creo que corresponde a la copia de la Madona del Passeggio del Museo del Prado (o/l, 100 x 34, $\mathrm{n}^{\circ}$ cat.: 314$)$.

47 Sobre la obra de Rafael en España y las copias de sus cuadros en España véase J. Ma . RuIz MANERo, Pintura Italiana del s. XVI en España II. Rafael y su Escuela, Madrid, 1996. Entre todas las obras por él recogidas ninguna puede identificarse con esta. Existen las copias del Padre de los Santos, realizadas a fines del siglo XVIII por lo que no pueden tratarse de la obra que de la que aquí hablamos pues sería del siglo XVI o XVII. Entre las copias que de Rafael se conservan en el Palacio Real de Madrid destaca una copia de La Perla con medidas muy parecidas (143,5 x 114, $\mathrm{n}^{\circ}$ inv.
} 10027232).

48 A. Ponz, Viaje por España, Tomo V, p. 41. 
Debía de tratarse de una obra de gran calidad pues ya era conocida cuando se encontraba en la Casa Profesa y así lo señaló el escultor real Felipe de Castro unos años antes de su adquisición ${ }^{49}$.

En este caso descubrimos un interés por la pintura del renacimiento clásico que se debe al cambio de los tiempos. La tasación de la obra es bastante alta por lo que debemos pensar que Mengs debió encontrar la copia de una excelente calidad.

Sin lugar a dudas las obras más importantes se encontraban en la Sacristía Mayor de la Casa Profesa pero junto a estas obras, y siguiendo el consejo de Mengs, el rey adquirió otras pinturas que se encontraban en el Camarín de San Francisco de Borja.

Recordemos que el motivo de la fundación de la Casa y el templo fue la intención de crear un espacio digno para la tumba del santo. En 1635 don Francisco de Borja, bisnieto del santo, arcediano de la catedral de Valencia y Capellán Mayor de las Descalzas Reales de Madrid decidió crear un patronato que regiría la nueva capilla camarín construida con su dinero, detrás del altar mayor, para una mayor veneración del santo jesuita. Parece ser que se realizó a modo de transparente tal y como parecen indicar los documentos que sobre la Casa Profesa se conservan. Así mismo, fue el propio Francisco de Borja el que se encargó de adornar lo más dignamente posible este Camarín, por lo que debemos suponer que fue él quien pagó o donó las obras de arte que en este espacio se encontraban ${ }^{50}$. Gracias al documento en el que se señalan las obras compradas por Carlos III podemos hacernos una idea de cómo estaba adornado este espacio.

En primer lugar se adquirió una Virgen con el Niño acompañada por ángeles ${ }^{51}$, obra de Andrea del Sarto. La obra es fácilmente identificable con la que se encuentra en el Museo del Prado: La Virgen, el Niño, san Juan y dos ángeles (Fig. 4. Óleo sobre tabla, 106 x 79, $\mathrm{n}^{\circ}$ Cat.: 338). Tanto el tema como las medidas coinciden por lo que no hay duda de su identificación ${ }^{52}$. Un cuadro idéntico, firmado, se conserva en la Colección Wallace de Londres $\left(1517-19,106\right.$ x 81, $\mathrm{n}^{\circ}$ inv.: P. 9) y es considerado por la crítica como obra original, de la que se habrían sacado numerosas copias dispersas hoy en día por todo el mundo entre las que podría estar la del Prado. Esto ha llevado a pensar que se dude de la autenticidad de la obra del museo madrileño, que podría tratarse de una de esas copias, en este caso de gran calidad, del original de la Wallace Collection ${ }^{53}$

49 C. BeDAT, 1968, op. cit., p. 215.

50 Los datos sobre el Camarín de San Francisco de Borja los conocemos gracias a las noticias que aporta su testamento cerrado ante Julián Jimeno el 17 de marzo de 1648 (AHN, Secc. Clero, Jesuitas, Libro 719, fol. 9: “y por quanto tengo hedificado y adornado la capilla de San Francisco de Borja mi señor y mi bisabuelo de tras del altar mayor de su Iglesia en la Casa Profesa de la Compañía de Jesús con trasparente a la urna donde están sus reliquias y soi fundador y patrón de ella y se me ha concedido entierro privativo debajo de las gradas del retablo del altar que he puesto"; fol. 10: "lo mejor y más precioso de mi oratorio y pinturas originales las he dado y colocado en ella (capilla camarín de San Francisco de Borja)". Copia de este testamento en AHN, Sec. Clero, Jesuitas, Leg 5582. En su mismo testamento legó numerosos objetos para el servicio de la Capilla de San Francisco de Borja, son todos objetos litúrgicos además de tapicerías que por lo extenso del documento no consideramos oportuno enumerar aquí.

Más noticias sobre esta capilla y su fundación se encuentran en el Libro Maestro en que se expresa..., (AHN, Secc. Clero, Jesuitas, Libro 341, f. 19 y ss.) y en AHN, Secc. Clero, Jesuitas, Leg. 717: "Copia del Informe que dio Agustín de Leiza Erasso hecho al Consejo sobre el extranamiento de los Regulares de la Casa Profesa..."

51 AGP, Secc. Carlos III, Cámara, leg. 88. Aparece de nuevo ya en las colecciones del Palacio Real de Madrid en 1772, fol. 999 v': "Ídem. Otro también en tabla, de nra señora con el niño, S. Juan, y otro Angelito de más de medio cuerpo y tamaño de la antecedente (de vara y quarto de alto, y vara escasa de ancho), escuela de Rafael". La descripción no es exacta pero posiblemente la cabeza del segundo ángel estaba muy oscura y no la vio. La atribución a la escuela de Rafael nos indica la falta de conocimiento de Calleja y las deudas de Sarto con su maestro. En el Inventario de 1788-89 estaba de nuevo atribuido a Sarto con una tasación bastante elevada de 4000 reales. Su ubicación en el oratorio reservado indica que gozaba de cierta estima por parte de Carlos III (1988, T. I, p. 24, nº 138).

52 En el mismo Museo del Prado existen dos copias (nos. Cat.: 333 y 339).

53 Así es considerada por la mayoría de los expertos como S. J. FREEDBERG (Andrea del Sarto. Catalogue Raisonné, Cambridge, Massachussets, 1963, p. 89), que cita como copias de la obra de la Wallace Gallery las tres del Prado. El éxito 
por lo que, o bien podría ser del propio Sarto, o bien realizada por su taller. Según Freedberg la obra de la Wallace Gallery se data hacia $1519-20^{54}$, por lo que nuestra obra debería ser posterior a esta fecha.

En el mismo camarín se encontraba otro de los cuadros comprados por Carlos III, se trata de El Nacimiento de Cristo, atribuido por Mengs a la escuela lombarda, lo que nos haría suponer que se trataba de un cuadro cercano, o incluso auténtico, de los Bassano, pintores que gozaron de gran estima en España a finales del s. XVI y de cuyas obras es frecuente encontrar referencias en los inventarios durante todo el s. XVII y XVIII ${ }^{55}$. Sin embargo, no es el caso de esta obra pues en el Inventario de 1772 el pintor Andrés de la Calleja, buen conocedor de la pintura española, aclara la autoría de la pintura. Así, la inventaría como: "Profesa. Un quadro que contiene el nacimiento de Christo, y adoración de los Pastores, de dos varas de largo y vara y quarto de cayda, original de Pedro Orrente" 56 . Si seguimos esta descripción y medidas debemos identificar esta obra con la que se encuentra en el Museo del Prado, La Adoración de los Pastores (Fig. 5. Óleo sobre lienzo, 111 x 162, no cat.: 1015). La obra fue calificada por Angulo y Pérez Sánchez como "una de sus mejores obras....muy basanesca", y, por analogías fisonómicas entre el rostro de la virgen y la Santa Leocadia de la Catedral de Toledo, la fechan hacia 161757. Es sin duda una de las mejores pinturas de Orrente en la que demuestra su conocimiento de la obra de los Bassano en cuyo taller, según Jusepe Martínez, estuvo aprendiendo al menos durante un año.

Los dos últimos cuadros que aparecen en la relación de cuadros comprados por Carlos III, y que también se hallaban en el camarín no han podido ser localizados. Se trata de dos obras menores. Una de ellas aparece citada de una manera muy escueta: "Un país de lámina...Pintado de Brugl"58. Suponemos que se trata de Jan Brueghel (1568-1625) y que representaría alguna escena de paisaje ${ }^{59}$. Su reducido tamaño (aprox. 20 x $15 \mathrm{~cm}$.) y el representar un tema tan genérico hace prácticamente imposible su identificación con alguna de las obras del Museo del Prado o de las Colecciones de Patrimonio Nacional. En 1772 se encontraba en el Palacio Real en el Paso del Dormitorio del Rey60. Por su tamaño se podría relacionar con un Incendio de Troya que en 1788 se encontraba en el Palacio Real, en el retrete del rey ${ }^{61}$. Sin embargo debemos pensar que no sería un tema muy apropiado para el camarín de un santo de la Contrarreforma por lo que no lo podemos asegurar

de esta obra fue muy grande pues el mismo Freedberg recoge al menos 28 copias entre las que destaca la existente en la Sacristía de la Catedral de Toledo (op. cit., p. 88-90). Sin embargo la del Prado es la que más se aproxima por medidas (casi idénticas) y representación a la de la galería londinense. Otros, ni siquiera la mencionan entre las obras de Andrea del Sarto como Natali, A.; CeCCHI, A., Andrea del Sarto, Catálogo Completo, Florencia, 1989, p. 72-72, nº 30.

54 FreEDBERG, op. cit., p. 87-90.

55 AGP, Carlos III, Leg. 88.

56 AGP, Administrativo, leg. 38, fol. 7 vo. Ubicada en el paso de Tribuna y trascuartos. En el Inventario de 1788-89, realizado a la muerte de Carlos III, se encontraba todavía en el Palacio Real de Madrid, en la Pieza encarnada (Inventarios Reales..., T. I, 1988, p. 51, $\mathrm{n}^{\circ}$ 453). Es interesante su tasación pues asciende a 4000 reales lo que supone una alta revalorización de la obra.

57 D. Angulo IÑiguez; A. E. Pérez SÁnchez, Historia de la Pintura Española. Escuela Toledana de la Primera Mitad del s. XVII, Instituto Diego Velázquez, Madrid, 1972, p. 243, nº 212. Esta deuda de Orrente hacia los modelos bassanescos conocidos en Italia hizo que Mengs atribuyese la pintura a un pintor Lombardo posiblemente ante el desconocimiento de la obra del pintor murciano.

58 AGP, Carlos III, leg. 88.

59 AGP, Carlos III, Leg. 88.

60 AGP. Administrativo, leg. 38. Pinturas del Nuevo Real Palacio. Echo en el año de 1772. Andrés de la Calleja. Fol. $25 \mathrm{v}^{\mathrm{o}}$ : "Casa Profesa. Otra en lamina que significa un país, de tercia escasa de alto, y menos de quarta de ancho; original de Brugul."

61 Inventarios Reales. Carlos III, 1788-89, 1988, p. 73, n 721: “Tercia de largo y quarta escasa de alto: El Yncendio de Troya. Brugul.....1500". 


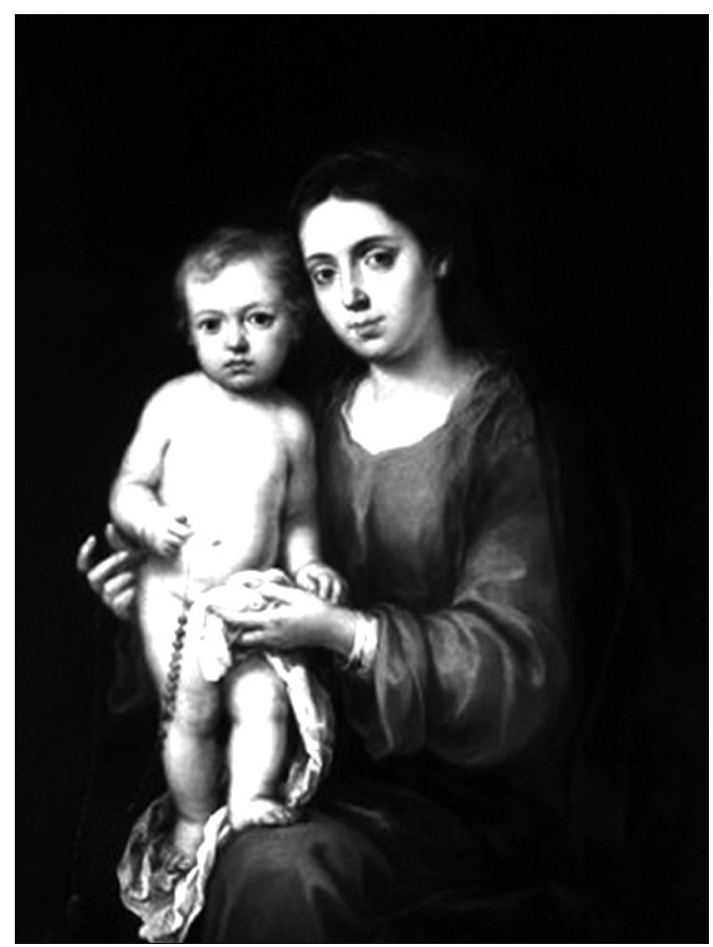

Fig. 3. Murillo. Virgen del Rosario.

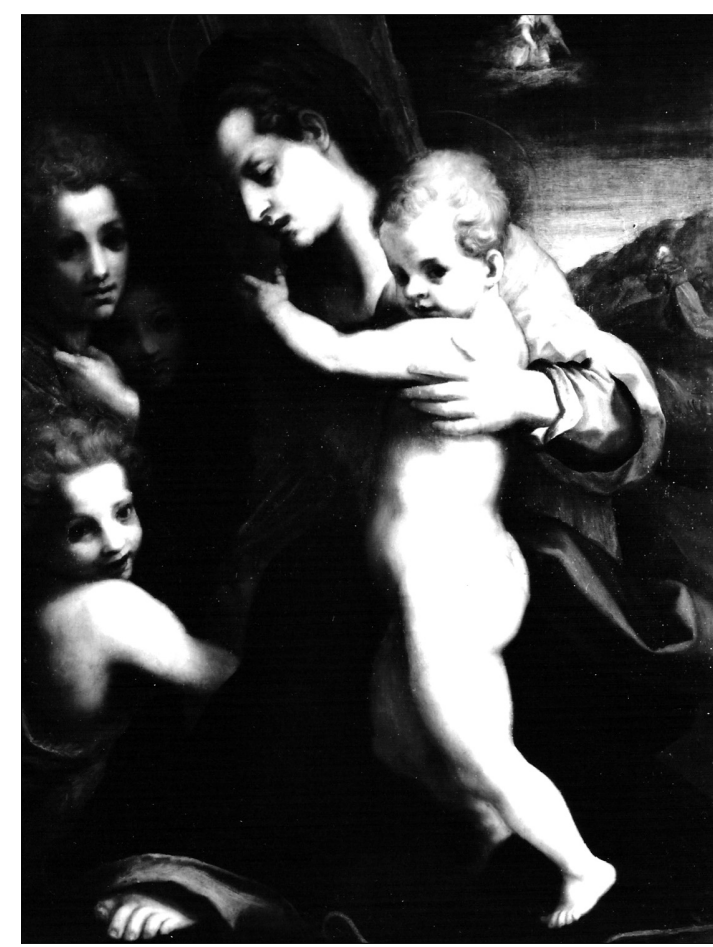

Fig. 4. Andrea del Sarto. Virgen, Niño y San Juanito.

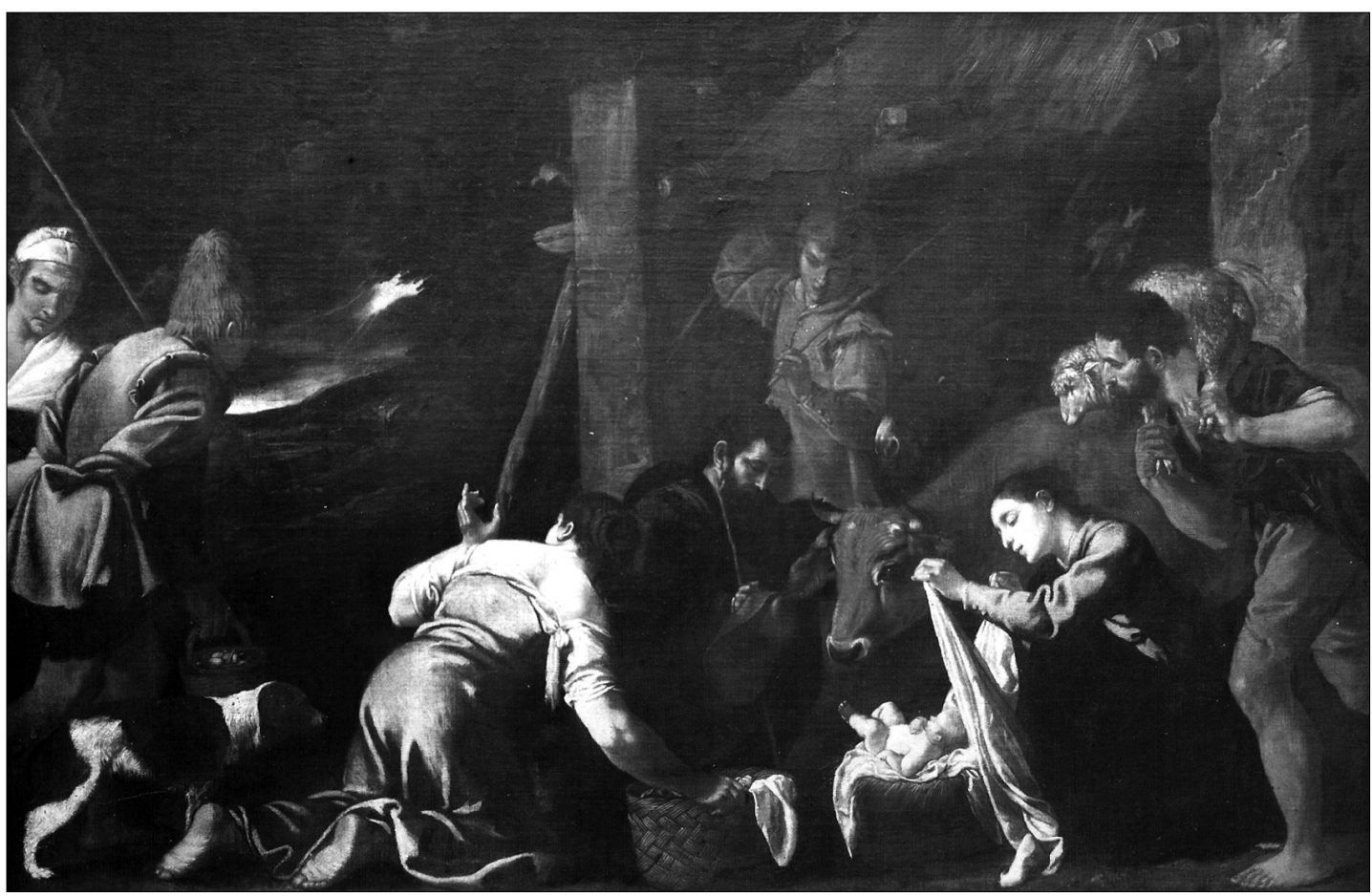

Fig. 5. Pedro Orrente. Adoración de los Pastores.

AEA, LXXX, 319, JULIO-SEPTIEMBRE 2007, 275-288, ISSN: 0004-0428 
con certeza. Actualmente, los paisajes de Brueghel que se conservan en Patrimonio Nacional proceden de la colección de Isabel de Farnesio. Sin embargo en el Palacio Real de Madrid se encuentra un Paisaje del artista $\left(12 \times 14 \mathrm{~cm} . \mathrm{n}^{\circ}\right.$ inv. 10010167) cuya procedencia se ignora y que por sus medidas y el conservarse en este palacio bien podría relacionarse con el de la Casa Profesa.

El último cuadro es una Coronación de Espinas, atribuido a Girolamo Muziano (1532-1592)62 o a su escuela ${ }^{63}$. Al parecer, según el inventario de 1772, al quedar sin destino pasó al Palacio del Buen Retiro ${ }^{64}$, lugar donde no aparece en el Inventario de 1788 . Poco podemos saber de esta obra pues como sucede con la anterior no hay ninguna pintura entre las colecciones del Museo del Prado y del Patrimonio Nacional que pueda ser relacionada con ella.

Esta es, pues, la lista de los cuadros que fueron comprados por Carlos III. Resulta, sin embargo, sorprendente la noticia de cómo Andrés Calleja tenía en su taller: "Dos quadros de la vida de San Juan Bautista y un Cristo Crucificado comprados en la Casa Profesa que se han forrado y añadido a fin de hacerlos yguales a otros y darles algún desahogo"65. La Crucifixión podría relacionarse con la obra de Muziano si bien recordemos que es una coronación de espinas como indican casi todos los inventarios. Los cuadros de la vida del Bautista no los hemos localizado.

Casi sin lugar a dudas todas las pinturas adquiridas del camarín de San Francisco de Borja debieron pertenecer a don Francisco de Borja. Ambas pinturas, la de Andrea del Sarto y la de Gerolamo Muziano habrían sido fáciles de adquirir tanto por el fundador del camarín como por su familia al pertenecer los dos pintores al mundo romano del s. XVI donde la familia Borja desarrollo una importantísima actividad política, religiosa y de mecenazgo. Lo mismo sucedería con una pequeña lámina de Jan Brueghel, también activo en Roma a fines del s. XVI y principios del s. XVII. Finalmente y de más fácil explicación es el origen de una obra de Pedro Orrente, activo en la ciudad del Turia durante bastantes años en el primer tercio del s. XVII, por lo que la presencia en la colección del arcediano de la catedral de Valencia, Francisco de Borja, no sería nada extraño y su donación al camarín por el fundador un origen muy verosímil.

Esto es lo que por ahora se puede saber sobre la casa Profesa de los Jesuitas de Madrid, así como de las pinturas que la decoraban y que fueron adquiridas por el monarca.

Recibido: 5-IX-2005

Aceptado: 10-I-2006

\footnotetext{
62 Este artista realizó algunas obras para Felipe II (Hija de Jairo, Monasterio de El Escorial). Además fue uno de los pintores favoritos de la corte Papal de Gregorio XII por lo que no resultaría extraño que la familia Borja tuviese algún contacto con él o con sus obras. Ver S. J. FreedBerg, Pintura en Italia 1500-1600, Madrid, 1992, p. 499-502.

63 AGP, Carlos III, Leg. 88.

64 AGP. Administrativo, leg. 38, fol. 53 vo., Pinturas del Nuevo Real Palacio. Echo en el año de 1772. Andrés de la Calleja. Estudio de Dn. Andrés de la Calleja. Pintor de Cámara de S. M. "casa Profesa. Un quadro, de Christo quando los saies le van a poner la corona de espins. De dos varas menos quarta de alto y varia y tercia de ancho." (en el margen: "este quedo sin destino y ahora esta en el retiro").

65 AGP. Leg. 49, Fernando VI, Casa, citado por Ma L. Arrero Sevillano, "La restauración de Pinturas de las Colecciones Reales durante el s. XVIII”, Archivo Español de Arte, 1980, nº 212, p. 490.
} 